\title{
Corporate political activity of the dairy industry in France: an analysis of publicly available information
}

\author{
Melissa Mialon ${ }^{1, *}$ and Jonathan Mialon ${ }^{2}$ \\ 'Mental Health and Addiction Research, Department of Health Sciences, University of York, ARRC Building, \\ Heslington, York YO10 5DD, UK: ${ }^{2}$ Independent Research Assistant, York, UK
}

Submitted 6 January 2017: Final revision received 10 April 2017: Accepted 10 May 2017: First published online 10 July 2017

\begin{abstract}
Objective: In the present study, we used a structured approach based on publicly available information to identify the corporate political activity (CPA) strategies of three major actors in the dairy industry in France.

Design: We collected publicly available information from the industry, government and other sources over a 6-month period, from March to August 2015. Data collection and analysis were informed by an existing framework for classifying the CPA of the food industry.

Setting/Subjects: Our study included three major actors in the dairy industry in France: Danone, Lactalis and the Centre National Interprofessionnel de l'Economie Laitière (CNIEL), a trade association.

Results: During the period of data collection, the dairy industry employed CPA practices on numerous occasions by using three strategies: the 'information and messaging', the 'constituency building' and the 'policy substitution' strategies. The most common practice was the shaping of evidence in ways that suited the industry. The industry also sought involvement in the community, establishing relationships with public health professionals, academics and the government. Conclusions: Our study shows that the dairy industry used several CPA practices, even during periods when there was no specific policy debate on the role of dairy products in dietary guidelines. The information provided here could inform public health advocates and policy makers and help them ensure that commercial interests of industry do not impede public health policies and programmes.
\end{abstract}

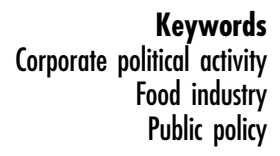

The dairy industry is an important economic actor in France, with over $€ 27$ billion in profits in $2013^{(1)}$. Dairy products have a special role in the diet of the population, with some products, such as milk, being one of the nine key food categories in the French Programme National Nutrition Santé (the French dietary and health guidelines), while some other products, particularly those high in fat, such as sour cream and butter, are considered as less healthy by the guidelines ${ }^{(2)}$.

Globally, there is an increased recognition that the economic power of the food industry often translates into political influence ${ }^{(3,4)}$. Corporate political activity (CPA) is a term used in the business literature to refer to the strategies used by industry to influence policy process and public opinion in ways favourable to the firm ${ }^{(5)}$. In public health, CPA has been widely studied for the tobacco industry, where public health advocates had access to internal documents after litigation against the industry in the late $1990 \mathrm{~s}^{(6-8)}$. These documents revealed that a broad range of CPA practices were used, over many decades, by the tobacco industry to influence public health policies and programmes ${ }^{(6,9)}$. A review conducted in 2015 by Mialon et al. showed that the food industry uses similar CPA strategies, which are classified in a framework presented in Table 1: the 'information and messaging' strategy; the 'financial incentives' strategy; the 'constituency building' strategy; the 'legal strategies'; the 'policy substitution' strategy; and the 'opposition fragmentation and destabilisation' strategy ${ }^{(10)}$. All of these strategies are used by companies to increase or protect their profits but could have a negative influence on the development of public health policies and programmes to address diet- and public health-related issues ${ }^{(10,11)}$.

In recent years, the influence of the French dairy industry on public opinion and on public health policies and programmes has been investigated by journalists ${ }^{(12,13)}$. They noted, for example, that this industry shaped the evidence base on diet- and public health-related issues and established relationships with policy makers ${ }^{(12,13)}$. 
Table 1 Description of corporate political activity (CPA) strategies and related practices of the food industry (from Mialon et al. ${ }^{(10)}$ )

\begin{tabular}{|c|c|}
\hline CPA strategy & Description and related practices \\
\hline Information and messaging & $\begin{array}{l}\text { The information strategy includes practices through which the industry disseminates information that is likely to } \\
\text { be beneficial to its activities to influence public health-related policies and outcomes in ways that are in its } \\
\text { favour. This strategy includes: lobbying policy makers; stressing the economic importance of the industry; } \\
\text { promoting deregulation; framing the debate on diet- and public health-related issues; and shaping the } \\
\text { evidence base on diet- and public health-related issues }\end{array}$ \\
\hline Financial incentives & $\begin{array}{l}\text { Through the financial incentives strategy, the industry provides funds, gifts and other incentives to politicians, } \\
\text { political parties and other decision makers }\end{array}$ \\
\hline Constituency building & $\begin{array}{l}\text { The aim of the constituency building strategy is to gain the favour of public opinion as well as other key stakeholders, } \\
\text { such as the media and the public health community. This strategy includes: establishing relationships with key } \\
\text { opinion leaders and health organisations; seeking involvement in the community; establishing relationships with } \\
\text { policy makers; and establishing relationships with the media }\end{array}$ \\
\hline Legal strategies & $\begin{array}{l}\text { In this strategy, the industry uses legal action (or the threat thereof) against public policies or opponents. The industry } \\
\text { may also attempt to influence the development of trade and investment agreements in its favour }\end{array}$ \\
\hline Policy substitution & $\begin{array}{l}\text { When threatened by regulation, the industry proposes alternatives, such as voluntary initiatives or } \\
\text { self-regulation }\end{array}$ \\
\hline $\begin{array}{l}\text { Opposition fragmentation and } \\
\text { destabilisation }\end{array}$ & $\begin{array}{l}\text { The opposition fragmentation and destabilisation strategy refers to practices employed by the industry to } \\
\text { fragment and destabilise groups or individuals that have criticised or are likely to oppose a company's products } \\
\text { or practices or policies that may adversely impact on the company }\end{array}$ \\
\hline
\end{tabular}

This political influence may compromise the development of effective public health policies and programmes, including dietary guidelines. However, to understand the extent to which the dairy industry uses CPA strategies, and in the absence of internal documents, public health advocates and researchers mostly rely on information available in the public domain. Mialon et al. proposed a structured approach, based on publicly available information only, to monitor the CPA of the food industry at the country level ${ }^{(10)}$.

We used the methods developed by Mialon et al. ${ }^{(10)}$ to monitor the CPA of three major actors in the dairy industry in France for a period of 6 months and report the results in the current paper.

\section{Methods}

We conducted a structured identification and monitoring of the CPA of major dairy industry actors in France over a 6-month period, as part of a broader project to monitor other sectors of the food industry in France. We collected publicly available information, using an approach that was based on previous approaches to identify and monitor the $\mathrm{CPA}$ of the tobacco and other industries ${ }^{(10)}$. This approach consisted of five steps: (i) selection of food industry actors; (ii) identification of sources of information; (iii) ongoing data collection; (iv) data analysis using the framework presented in Table 1, in an iterative process; and (v) reporting of results for policy action.

Selection of industry actors was based on recommendations made by Mialon et $a l .^{(10)}$. Due to time constraints, and after consultation with experts, we decided to include three industry actors in our study. We monitored the CPA of two major actors in the 'packaged products, dairy' category in France, based on the Euromonitor classification of companies ${ }^{(14)}$. The selection was based on their market shares: in 2014, the Groupe Lactalis (referred to as
'Lactalis' herein) and the Groupe Danone (referred to as 'Danone' herein) owned $17 \cdot 1$ and $8.0 \%$ of that market, respectively. In addition, we included the Centre National Interprofessionnel de l'Economie Laitière (CNIEL, the National Inter-professional Centre for the Dairy Economy) in our study ${ }^{(15)}$. In France, the CNIEL is a major trade association for the dairy industry and has two principal objectives: foster the relationships between producers and processors in the dairy food chain and promote the image of milk and dairy products,(16).

Different sources of information were included: the industry's own materials, including its websites and Twitter accounts; government materials, such as registers of lobbyists or websites of agencies in charge of healthrelated issues; and other materials, including the websites of universities and professional organisations ${ }^{(10)}$. Google News and media releases from the selected sample of actors were also analysed. For annual or occasional events and publications, including conferences or companies' annual reports, we included the most recent data available (up to 2 years retrospectively). Data collection covered the period March-August 2015. It is important to note that during this period, there was no specific debate on the role of dairy products in the dietary guidelines. Details about specific sources of information are provided in the online supplementary material, Supplemental Table 1. All documents retrieved were in French and collected and analysed by a native French-speaker.

J.M. conducted the data collection and qualitative analysis. Choice of themes was based on an existing framework for categorising the CPA strategies of the food industry ${ }^{(10)}$. Categorisation of data $(100 \%)$ was reviewed by the second author, M.M., and mutual agreement was reached (but not quantified) for the final categorisation of CPA practices. All data collected are available in French in the online supplementary material, Supplemental Table 2.

In the current paper, we present illustrative examples (each allocated with an 'A' code from Supplemental Table 2), 
translated from French to English, of CPA practices employed in France by three major actors in the dairy industry during the period of data collection. We use the broad term 'dairy industry' to refer to the three industry actors included in our study.

We took a critical social science approach, where actions of the food industry were considered a potential determinant of health. Critical social science seeks to reduce illusion; in this case, the illusion is that the dairy industry is only an economic actor, while it also engages in political activities. Critical social science also seeks to identify avoidable suffering. In this case, the potential suffering comes from the fact that commercial interests of the dairy industry may impede public health policies and programmes, thus having a negative impact on the health of the population ${ }^{(17)}$.

\section{Results}

During the period of data collection, evidence shows that the dairy industry used three of the six CPA strategies identified in the literature, with 170 examples collected over a 6-month period. Table 2 presents a summary of the examples we found for each of the CPA practices.

In France, the dairy industry made extensive use of the 'information and messaging' strategy in particular and there was evidence that it also used the 'constituency building' and 'policy substitution' strategies to a lesser extent. We found no evidence, from the data we collected in the public domain, of the 'financial incentives', 'legal' and 'opposition fragmentation and destabilisation' strategies.
The absence of information on the 'financial incentives' strategy could be explained by the fact that French laws prohibit political parties from receiving individual donations that exceed $€ 7500^{(18)}$.

\section{Information and messaging}

In France, during the period of data collection, the dairy industry mostly used the 'information and messaging' strategy. One hundred and twenty-nine of the 170 examples we collected were classified within that strategy.

\section{Stressing the economic importance of the industry}

First, the economic importance of the dairy industry was highlighted on several occasions by the CNIEL: it emphasised the number of jobs it generated, particularly in remote regions, and stressed the fact that this industry was a driving force in the French economy (A76-A81).

\section{Framing the debate on diet-and public health-related issues}

The dairy industry also promoted messages on diet-related issues. Even if they might be accurate, the fact that the industry promoted only certain messages indicates framing in ways favourable to its products. For example, despite working with food products, the industry focused attention on physical activity programmes, a practice that has been used by other companies, in other countries, to shift the blame away from industry products in the global burden of non-communicable diseases ${ }^{(19,20)}$. These messages included:

'To support teachers during the academic year, the Danone Institute France, in collaboration with the Union Sportive de l'Enseignement du Premier degré

Table 2 Summary of examples of corporate political activity (CPA) strategies identified for the selected dairy industry actors in France

\begin{tabular}{|c|c|c|c|c|c|c|}
\hline \multirow[b]{2}{*}{ Strategy } & \multirow[b]{2}{*}{ Practice } & \multirow[b]{2}{*}{ Danone } & \multirow[b]{2}{*}{ Lactalis } & \multirow[b]{2}{*}{ CNIEL } & \multicolumn{2}{|c|}{ Total (examples) } \\
\hline & & & & & Row & Overall \\
\hline \multirow[t]{5}{*}{ Information and messaging } & Lobbying & 0 & 0 & 0 & 0 & 129 \\
\hline & Stress the economic importance of the industry & 1 & 1 & 6 & 8 & \\
\hline & Promote deregulation & 0 & 0 & 0 & 0 & \\
\hline & $\begin{array}{l}\text { Frame the debate on diet- and public health-related } \\
\text { issues }\end{array}$ & 2 & 0 & 4 & 6 & \\
\hline & $\begin{array}{l}\text { Shape the evidence base on diet- and public health- } \\
\text { related issues }\end{array}$ & 26 & 7 & 82 & 115 & \\
\hline Financial incentives & Financial incentives & 0 & 0 & 0 & 0 & 0 \\
\hline \multirow[t]{4}{*}{ Constituency building } & $\begin{array}{l}\text { Establish relationships with key opinion leaders and } \\
\text { health organisations }\end{array}$ & 3 & 2 & 2 & 7 & 38 \\
\hline & Seek involvement in the community & 12 & 0 & 1 & 13 & \\
\hline & Establish relationships with policy makers & 13 & 1 & 4 & 18 & \\
\hline & Establish relationships with the media & 0 & 0 & 0 & 0 & \\
\hline \multirow[t]{2}{*}{ Legal strategies } & $\begin{array}{l}\text { Use legal action (or the threat of) against public policies or } \\
\text { opponents }\end{array}$ & 0 & 0 & 0 & 0 & 0 \\
\hline & $\begin{array}{l}\text { Influence the development of trade and investment } \\
\text { agreements }\end{array}$ & 0 & 0 & 0 & 0 & \\
\hline Policy substitution & Policy substitution & 3 & 0 & 0 & 3 & 3 \\
\hline $\begin{array}{l}\text { Opposition fragmentation and } \\
\text { destabilisation }\end{array}$ & Opposition fragmentation and destabilisation & 0 & 0 & 0 & 0 & 0 \\
\hline $\begin{array}{l}\text { Total number of CPA practices } \\
\text { identified }\end{array}$ & & 60 & 11 & 99 & 170 & 170 \\
\hline
\end{tabular}

CNIEL, Centre National Interprofessionnel de l'Economie Laitière. 
(USEP - Sport Alliance for Primary Schools), developed the kit "Let's move".' (A20)

'No food, in itself, is responsible for the obesity epidemic, neither milk, nor any other food. (...) It is when energy expenditure (physical activity...) is below intake (diet) that we may gain weight, it is a question of balance.' (A82)

\section{Shaping the evidence base on diet-and public health- related issues}

In the present study we found that one of the major practices of the dairy industry was to shape the evidence on dietrelated issues. One hundred and fifteen of the 170 examples collected during our study referred to that practice. It did so using different mechanisms. One of them was to establish and run scientific organisations. Through these organisations, the industry publicised the beneficial health effects associated with the consumption of dairy products. For example, the 'Danone Institute provide(s), for free, "Nutrition Objective" to almost 21000 health professionals. (...). Written by diet and nutrition specialists, Nutrition Objective proposes original, up-to-date and practical scientific knowledge' (A12). And, 'for the Danone Institute France, supporting research has always been a priority. Since its beginning, the Institute has awarded research prizes to young researchers. Thus, in 20 years, the Institute has supported more than seventy-five researchers' (A17). Another example was the CERIN, 'a research and nutrition information centre and the health department of the dairy industry', whose 'mission is to deliver comprehensive and validated nutritional information about milk and dairy products, but also about the general themes of nutrition and health, nutritional needs of subgroups of the population, and the prevention of pathologies through nutrition, to health and public health professionals, but also to journalists' (A164). A third example was OCHA, which is the observatory of eating habits for the dairy industry - it is a resource and research centre shared with the scientific community around the approach, using human and social sciences, of diet, food systems and relations man/ animal' (A162). We noted that the link with the dairy industry was not always made clear on the organisations' websites. For example, there were mentions of the industry's affiliation with the CERIN on the different websites we searched, and the OCHA's description on its website header was 'the CNIEL observatory of eating habits' (A162). However, one would have needed to know what the CERIN or CNIEL was in order to make a connection with the dairy industry.

The dairy industry also promoted industry-sponsored educational materials for health professionals, such as television shows (A155). The CERIN also supplied educational materials on its website:

'The CERIN leaflets are summary materials for the general public and patients relaying recommendations and dietary advice. (...) The basics (leaflets, basic sheets and posters) could be ordered for free.
(...) The synthetic and informative posters are intended for the waiting rooms of health professionals. They could also be used to support food education sessions.' (A161)

The industry did not systematically provide references to scientific studies (A10, A21, A23, A24, A66-A68, A70, A71 and several examples through A86-A169). In addition, there were examples where the dairy industry provided and used evidence that had links to or that was funded by the industry itself (A127, A129, A130, A157, A159). On several occasions, the dairy industry presented unpublished and non-peer reviewed evidence when discussing the health benefits associated with the consumption of dairy products (A93, A95-A98, A123, A131). This is a practice that has been described in the literature for the tobacco industry ${ }^{(21)}$.

In addition, it promoted the health benefits of specific, single nutrients, and, because these were present in some dairy products, implied that these products were good for health, but did not provide scientific references to support those claims. For example, there were messages claiming that:

'For health professionals, cheese is primarily a source of calcium and protein. They recognise that it has a role in the prevention of denutrition and osteoporosis. Yoghurt is acclaimed for easing digestion. As for milk, it is all good! It is a complete food; it provides calcium but also protein, vitamins and trace elements.' (A139)

'Is butter good for health? Butter is often criticised for being rich in saturated fatty acids, and for increasing cholesterol. In fact, butter is made up of a large variety of different fatty acids: saturated (including the shortchain saturated, good for health) but also unsaturated (poly and mono-unsaturated). In practice, all types of fats have a nutritional value. The important thing is to vary them (...). Butter is also very rich in vitamin A, beneficial for vision and growth: 20 to $25 \mathrm{~g}$ of butter a day could cover approximately $30 \%$ of the daily intake in vitamin A.' (A153)

Another CPA practice of the dairy industry was to actively participate in most of the major diet- and public health-related scientific events in France. For example, there were several partners from the food industry at the 'Entretiens de Nutrition de l'Institut Pasteur de Lille' (Annual national nutrition talks), including some actors from the dairy industry, such as Danone and the CERIN (A8, A89). The dairy industry was also involved in the 'Journées Francophones de Nutrition' (Annual nutrition conference for Francophones): the CERIN was an official partner and ran a symposium, while Danone organised its ' $20^{\mathrm{eme}}$ Rencontres Scientifiques de Nutrition' (20th scientific meeting on nutrition) on the health effects of food contaminants in parallel with the conference (A14, A87, A88). 
There was also evidence that the ' $53^{\text {eme }}$ journées d'études de l'Association Française des Diététiciens Nutritionnistes' (Annual conference of the Dieticians and Nutritionists Association of France) was organised in partnership with the three dairy industry actors included in our study (A29, A72, A165). In addition, Danone provided donations to the Fonds Français pour l'Alimentation et la Santé or FFA (French funds for diet and health), an 'unprecedented and unifying structure whose mission is the study and enhancement of diet as a source of pleasure and health' (A27). In 2015, the FFA supported research and community programmes, received funds from food companies and trade associations, and was administered by an equal mix of stakeholders from the research/academic sector and from industry (A27) $)^{(22)}$.

The dairy industry also provided educational material to children, some of which may be considered as 'advergaming' (simultaneous 'advertising' and 'gaming') ${ }^{(23,24)}$, with the intention to actively promote the benefits of consuming dairy products to that population:

'The website www.power-cows.fr was developed by the CNIEL to inform adolescents in secondary school (...) about the benefits of consuming the 3 to 4 dairy products a day that are recommended by the Plan National Nutrition Santé [French dietary and health guidelines].' (A110)

'The CNIEL proposes a free notebook for the holidays available on tablets and smartphones, to allow children ages 6 to 11 years old to discover how milk is produced, how it is processed and what are the nutritional benefits of dairy products. A fun way to educate young people about the dairy sector.' (A142)

'Les Jeunes Agriculteurs du Grand OUEST [The young farmers of the Midwest] have been offering activities for several years in the primary schools of the region, through a partnership with the Inspection Académique de la Sarthe [Department of Education in the Sarthe region] and the CNIEL. (...) The objective of the JA was not to replace dieticians or doctors, but to be able to give an answer to all these sensitive questions.' (A138)

\section{Constituency building}

We also found evidence that the dairy industry used the 'constituency building' strategy, where it tried to establish relationships with different stakeholders. For example, Danone conducted research in partnership with public research institutes in France (INRA, Agro Paris Tech) and abroad (the University of Southampton; A43). Danone also sought involvement in the community, through programmes focusing on nutrition, water, sanitation and hygiene, and was a partner of the French Red Cross and of the French branch of the Ronald McDonald Foundation (A30-A32, A39-A41). During the period of data collection,
Danone (in partnership with the food company Mars) launched the 'Livelihood fund' for small farmers, an event which was publicised in several newspapers (A33-A38).

In addition, the dairy industry established relationships with the French government. For example, the Conseil National de l'Alimentation (French National Food Council) is described, on its website, as an institution 'under the auspices of the Ministry of Agriculture, Ministry of Health and Ministry in charge of consumer affairs. (...) This council is consulted about the definition of public food policy and provides its expertise on related questions' (A169). One of its members was affiliated with the CNIEL (A169).

There were other links between the dairy industry and the government:

'Le Programme Alimentation et Insertion (PAI) [Programme food and employability] is an approach (...) that offers training about food balance and social bonding. (...) Launched in September 2003 by Dominique Versini, then-Secretary of State for the fight against precariousness and exclusion, it embodies a partnership commitment in the field of food and nutritional aid, bringing together the government, food banks and several sponsors represented by the ANIA [a trade association], including the Foundation Nestle France and the CNIEL.' (A168)

'For almost thirty years, the dairy industry has built close relationships with the Ministry of Education, through actions targeting teaching staff, management staff and students. The objective: introducing dairy products to children and adolescents.' (A90, also cited in A174)

Evidence also showed that several ANSES experts (the French Agency for Food, Environmental and Occupational Health \& Safety), particularly those working in the 'human nutrition' committee, had close links with the dairy industry: some provided their expertise to the industry scientific organisations, some conducted research in which the industry was involved and others had personal or financial ties with the industry (A45-A55, A75, A86, A171A173). Data showed that an ANSES expert working for the 'human nutrition' committee, as well as two senators and a member of parliament, owned shares in Danone in 2015 (A61-A64). It is crucial to note that French laws prohibit public servants, including ANSES experts, to work on matters for which they have a personal, even if indirect, conflict of interest ${ }^{(25)}$. The ANSES has internal procedures to ensure the implementation of the law within the agency $^{(26)}$.

\section{Policy substitution}

Finally, we found evidence, although limited, that the dairy industry used the 'policy substitution' strategy. For example, some of Danone's companies, under the auspices of the 
Ministry of Health, voluntarily committed to improving the nutritional content of their products (A60).

\section{Discussion}

In the present study, we found evidence, from the public domain, that the dairy industry was using several CPA strategies in France in 2015, with a total of 170 examples collected over a 6-month period. The three industry actors included in our study extensively employed the 'information and messaging' strategy, with a total of 129 examples of our 170 examples found in that category. The shaping of evidence in ways that suited the industry was the most common practice within this category, with 115 examples for this practice alone. For example, the dairy industry set up health organisations through which it publicised the beneficial health effects associated with the consumption of dairy products. The dairy industry also promoted industrysponsored educational materials for health professionals, information that was either unpublished or not peerreviewed, or funded by the industry, and participated in major diet- and public health-related scientific events in France. The industry also used the 'constituency building' strategy, and sought involvement in the community, through partnerships with different charities, and established relationships with public health professionals, academics and the government, such as the ANSES and the Ministry of Education. In addition, we found evidence, although limited, that the dairy industry was using the 'policy substitution' strategy. Our study shows that the dairy industry used several CPA practices, even during periods when there was no specific policy debate on the role of dairy products in the dietary guidelines. We found no evidence of the 'financial incentives', 'legal' and 'opposition fragmentation and destabilisation' strategies.

The current study is the first, to our knowledge, to study the CPA of the food industry in France. It is the first study that focused on the CPA of the dairy industry. It used methods that have previously been successful in exploring the CPA of other major industry actors in other countries where researchers did not have access to internal documents. The framework by Mialon et al. seemed comprehensive and we were able to include all our data under these framework categories ${ }^{(10)}$. This work could contribute to INFORMAS, the International Network for Food and Obesity/noncommunicable diseases Research, Monitoring and Action Support ${ }^{(27)}$. This network monitors different aspects of food environments in different countries, including the CPA of the food industry. The present study, if replicated in other countries, could contribute to comparisons of industry practices among, across and over time, for different sectors of the food industry, and to comparisons of dairy industry practices (and of the food industry more generally) with the practices of other industries, nationally and globally.

For example, recent studies showed that the food industry made extensive use of CPA strategies in Australia and in Fiji, two countries of the Western Pacific region ${ }^{(19,20,28)}$. The results of the current study, although not focused on the same sector of the food industry, are very similar. In Australia, Fiji and France, the actors stressed their economic importance on numerous occasions ${ }^{(19,20,28)}$. In all countries, they also promoted physical activity in an attempt to frame the debate on diet- and public health-related issues ${ }^{(19,20,28)}$. In Australia and France, the actors included in the studies shaped the evidence on diet- and public health-related issues, for example by citing evidence that was funded by the industry and by using non-peer reviewed and unpublished evidence ${ }^{(19,28)}$. The industry actors tried to establish relationships with health organisations or experts in both these countries ${ }^{(19,28)}$. In Australia, Fiji and France, the industry actors provided educational materials to children, sought involvement in the community, established relationships with policy makers and used, to some extent, the 'policy substitution' strategy ${ }^{(19,20,28)}$. However, as with previous studies, there was no evidence (or limited evidence for Australia), in the public domain, that the industry actors employed the 'legal' and the 'opposition fragmentation and destabilisation' strategies ${ }^{(19,20)}$. In that sense, these results show that the CPA of the dairy industry is no different from the CPA of other sectors of the food industry, and the CPA of industry actors in France is also comparable to the CPA of other industry actors around the globe.

Our study has a number of limitations. First, we selected a limited number of primary sources in our study, as described by Mialon et al. ${ }^{(10)}$. Our search was therefore not exhaustive. It is crucial to note that an absence of evidence, or limited evidence, of CPA practices does not mean that the industry is not using them. One explanation could be that we missed this information. Another explanation might be that the industry is using CPA strategies without disclosing it in the public domain, which is more problematic. This could also be explained by the fact there are safeguards in place to ensure that the industry does not influence public health policies and programmes, such as laws prohibiting donations to political parties, but these results warrant further investigation.

Research conducted in other countries showed that interviews with key informants might reveal additional and critical details about the $\mathrm{CPA}^{(20,28)}$. For example, informal connections and meetings between industry actors and government officials might not be recorded in the public domain, yet they could be very influential. Therefore, we recognise that relying uniquely on data available in the public domain might not be sufficient to identify all CPA strategies. In addition, we focused on specific industry actors for the current study, and their actions may not represent the actions of other actors in their sector or in the food industry more broadly. Similarly, we conducted our research in 2015 and further investigation is needed to understand how the use of CPA strategies by this industry varies over time. Finally, the industry actors included in our study are part of some other groups or organisations listed in the online 
supplementary material, Supplemental Table 3, but, due to time constraints, we did not collect data for these groups.

Some have questioned the scientific evidence for recommending the consumption of several dairy products daily, as is the case in France (three or four products), and classifying it as a separate category in the dietary guidelines ${ }^{(12,13,29)}$. In light of the results provided here and the CPA strategies of the dairy industry in France, particularly its shaping of evidence, more research is needed to understand if these practices had, and continue to have, an influence on the development of the French dietary guidelines and similar policies and programmes. The results from the current study could raise awareness of potential dairy industry interference with public health policies and programmes, including its involvement in some activities that may otherwise have been seen as beneficial, such as its focus on physical activity, its sponsorship of scientific organisations and its support for the community. The study also raises questions about the appropriate role of the dairy industry in interactions with public health professionals and government, and the potential conflicts of interest that make such interactions problematic for public health policy making. The information provided herein could be used by public health advocates and the public to increase the transparency and accountability of the dairy industry, and other sectors of the food industry more generally. The study could be replicated for longer periods of time, with other industry actors and other industries in France and abroad. This could help to identify the extent of the involvement of the food industry in public health policies and programmes in France and ensure that commercial interests of industry do not impede public health policies and programmes.

\section{Acknowledgements}

Financial support: This research did not receive any specific grant from any funding agency in the public, commercial or not-for-profit institutions. Conflict of interest: None. Authorship: M.M. participated in the formulation of the research question, in the design of the study, supervised the data collection and analysis, and drafted the manuscript. J.M. participated in the design of the study, carried out the data collection and analysis, and critically reviewed the manuscript. Ethics of human subject participation: Not applicable.

\section{Supplementary material}

To view supplementary material for this article, please visit https://doi.org/10.1017/S1368980017001197

\section{References}

1. Les produits laitiers (2013) Economie laitiere en France. http://www.produits-laitiers.com/l-economie-laitiere-en-france/ (accessed December 2016).
2. Institut national de prévention et d'éducation pour la santé (2016) Alimentation/Déterminants de l'état nutritionnel/ Les produits laitiers à tous les âges de la vie. http://www. mangerbouger.fr/pro/sante/alimentation-19/determinantsde-l-etat-nutritionnel/les-produits-laitiers-a-tous-les-ages-dela-vie.html (accessed December 2016).

3. World Health Organization (2013) Opening Address at the 8th Global Conference on Health Promotion Helsinki, Finland, 10 June 2013 by Dr Margaret Chan DirectorGeneral of the World Health Organization. http://www. who.int/dg/speeches/2013/health_promotion_20130610/en/ (accessed June 2017).

4. Moodie R, Stuckler D, Monteiro C et al. (2013) Profits and pandemics: prevention of harmful effects of tobacco, alcohol, and ultra-processed food and drink industries. Lancet 381, 670-679.

5. Hillman AJ, Keim GD \& Schuler D (2004) Corporate political activity: a review and research agenda. J Manage 30, 837-857.

6. Saloojee Y \& Dagli E (2000) Tobacco industry tactics for resisting public policy on health. Bull World Health Organ 78, 902-910.

7. Bero L (2003) Implications of the tobacco industry documents for public health and policy. Annu Rev Public Health 24, 267-288.

8. University of California San Francisco (2013) Legacy Tobacco Documents Library. http://legacy.library.ucsf.edu/ (accessed December 2013).

9. World Health Organization (2009) Tobacco Industry Interference with Tobacco Control. Geneva: WHO.

10. Mialon M, Swinburn B \& Sacks G (2015) A proposed approach to systematically identify and monitor the corporate political activity of the food industry with respect to public health using publicly available information. Obes Rev 16, 519-530.

11. Lawton T, McGuire S \& Rajwani T (2013) Corporate political activity: a literature review and research agenda. Int $J$ Manage Rev 15, 86-105.

12. Souccar T (2008) Lait, mensonges et propaganda, 2nd ed. Vergèze: T. Souccar.

13. Richez-Lerouge V (2016) La vache qui pleure! retour au lait naturel, une question de santé. Paris: Nouveau monde éditions.

14. Euromonitor International (2013) Euromonitor Passeport. http:// www.portal.euromonitor.com/Portal/ (accessed November 2016).

15. Sacks G, Swinburn B, Kraak V et al. (2013) A proposed approach to monitor private-sector policies and practices related to food environments, obesity and noncommunicable disease prevention. Obes Rev 14, 38-48.

16. Centre National Interprofessionnel de l'Economie Laitière (2016) Le CNIEL, Maison du lait. http://www.maison-du-lait. com/les-organisations/cniel (accessed August 2016).

17. Sayer A (2009) Who's afraid of critical social science? Curr Sociol 57, 767-786.

18. LegiFrance (2013) Loi no 88-227 du 11 mars 1988 relative à la transparence financière de la vie politique: Article 11-4. https:// www.legifrance.gouv.fr/affichTexteArticle.do?idArticle $=$ LEGIARTI000006355325\&cidTexte=JORFTEXT000000 321646 (accessed December 2016).

19. Mialon M, Swinburn B, Allender S et al. (2016) Systematic examination of publicly-available information reveals the diverse and extensive corporate political activity of the food industry in Australia. BMC Public Health 16, 283.

20. Mialon M, Swinburn B, Wate J et al. (2016) Analysis of the corporate political activity of major food industry actors in Fiji. Global Health 12, 18.

21. Ulucanlar S, Fooks GJ, Hatchard JL et al. (2014) Representation and misrepresentation of scientific evidence in contemporary tobacco regulation: a review of tobacco 
industry submissions to the UK Government consultation on standardised packaging. PLOS Med 11, e1001629.

22. Fonds Francais pour l'Alimentation et la Sante (2015) Rapport d'activites - Annee 2015. http://alimentation-sante.org/wpcontent/uploads/2016/06/RA_2015_vfinale.pdf (accessed June 2017).

23. Simon M (2006) Appetite for Profit: How the Food Industry Undermines Our Health and How to Fight Back. New York: Nation Books.

24. Brownell KD \& Warne KE (2009) The perils of ignoring history: Big Tobacco played dirty and millions died. How similar is Big Food? Milbank Q 87, 259-294.

25. LegiFrance (2013) Code Penal Article 432-12. https://www. legifrance.gouv.fr/affichCodeArticle.do?cidTexte=LEGITEXT 000006070719\&idArticle $=$ LEGIARTI000006418521\&date Texte $=\&$ categorieLien $=$ cid $($ accessed December 2016).
26. French Agency for Food, Environmental and Occupational Health \& Safety (2010) Code de déontologie de l'expertise de l'Agence nationale de sécurité sanitaire de l'alimentation, de l'environnement et du travail. vol. 1. Paris: ANSES.

27. Swinburn B, Sacks G, Vandevijvere S et al. (2013) INFORMAS (International Network for Food and Obesity/ non-communicable diseases Research, Monitoring and Action Support): overview and key principles. Obes Rev 14, $1-12$.

28. Mialon M, Allender S, Swinburn B et al. (2017) 'Maximising shareholder value': a detailed insight into the corporate political activity of the Australian food industry. Aust $N Z J$ Public Health 41, 165-171.

29. Nestle M (2002) Food Politics: How the Food Industry Influences Nutrition and Health, California Studies in Food and Culture. Berkeley, CA/London: University of California Press. 